\title{
Fetal Behavior in Normal Pregnancy and Diabetic Pregnancy
}

\author{
${ }^{1}$ Asim Kurjak, ${ }^{2}$ Sonal Panchal, ${ }^{3}$ Selma Porovic
}

\begin{abstract}
Ultrasound (US) has been the modality of choice for assessment of the development of the embryo and fetus in the womb. Threedimensional US has made the study of the fetal anatomy even more accurate and understandable. But fetal development is not only the development of the structures but also their functionality. The functionality of the kidneys, e.g., can be confirmed by urine production and filling of the bladder, the functionality of the bladder by its periodically emptying and filling, and that of the heart by fetal circulation. The function of the nervous system is the most complex and this can be studied by fetal movements and fetal expressions. The development of fetal motor behaviors can be studied by real-time US. ${ }^{1}$ The fetal activity observed or recorded with US equipment is fetal behavior. ${ }^{2}$

Study of the fetal movements has been found to be more correlating with the fetal central nervous system (CNS) development. Studies have shown that the development and maturation of the fetal nervous system is reflected by quality and quantity of fetal movements. ${ }^{3,4}$ On comparing the fetal movements with morphological studies, it was found that the fetal behavioral patterns directly reflected the development and maturation of fetal CNS. Therefore, assessment of fetal behavior in different periods of gestation can help to distinguish normal brain from abnormal during different phases of development. ${ }^{5}$ It also helps to make the diagnosis of functional and structural abnormalities earlier. ${ }^{6}$

B-mode or a two-dimensional (2D) US is impossible to understand the complexity of these movements and so till the invent of four-dimensional (4D) US it was not possible to correctly evaluate the fetal movements, especially fetal expressions. The details of fetal face and hands studied by 4D US have potential to generate information regarding fetal movement and behavior. ${ }^{7}$ There is a specific fetal behavioral pattern that corresponds to each week or trimester of fetal life and this pattern reflects the steps of human brain development and maturation. ${ }^{8-10}$
\end{abstract}

Keywords: Diabetic pregnancy, Fetal behavior, Kurjak's antenatal neurodevelopmental test, Normal pregnancy.

How to cite this article: Kurjak A, Panchal S, Porovic S. Fetal Behavior in Normal Pregnancy and Diabetic Pregnancy. Donald School J Ultrasound Obstet Gynecol 2018;12(2):124-136.

Source of support: Nil

Conflict of interest: None

${ }^{1}$ Professor Emeritus, ${ }^{2}$ Professor and Consultant, ${ }^{3}$ Specialist

1 Department of Obstetrics and Gynecology, School of Medicine University of Zagreb, Zagreb, Croatia

${ }^{2}$ Department of Ultrasound, Dr. Nagori's Institute for Infertility and IVF, Ahmedabad, Gujarat, India

${ }^{3}$ Department of Preventive and Pediatric Dentistry, Public Health Center of Sarajevo Canton, Sarajevo, Bosnia and Herzegovina

Corresponding Author: Sonal Panchal, Professor and Consultant, Department of Ultrasound, Dr. Nagori's Institute for Infertility and IVF, Ahmedabad, Gujarat, India, e-mail: sonalyogesh@yahoo.com

\section{UNDERSTANDING THE NORMAL FETAL ACTIVITY}

Spontaneous fetal movements can be observed using 2D US around eighth gestational week, but 4D US may show fetal motility at seventh week of gestation on transvaginal scans. ${ }^{11,12}$ From 10 weeks onward the frequency of fetal movements increases and are maximum between 14 and 19 weeks. ${ }^{12}$ The longest interval between movements at this age is 5 to 6 minutes. Between 9 and 14 weeks of fetal age, mostly general movements (GMs) are observed. ${ }^{13}$ Using $4 \mathrm{D}$ sonography, Kurjak et $\mathrm{al}^{14}$ found that from 13 th gestational weeks onward, a "goal orientation" of hand movements (Fig. 1) appears and a target point can be recognized for each hand movement. At 15 weeks, 15 different types of movements have been recorded. ${ }^{15}$ But according to a study by Kurjak et al, ${ }^{16} 16$ different types of movements can be observed at 15 weeks of gestation. Eye movements are detectable at 16 to 18 weeks, organized complex movements at 20 weeks, and facial expressions also start at 20 weeks. ${ }^{17}$ Facial expressions like smiling, yawning, eyelid movement, mouthing, grimacing, tongue expulsion/swallowing, and sucking were observed during second and third trimesters. Mouthing was the most frequent facial movement during early third trimester, whereas scowling and sucking were the least frequent. ${ }^{15-18}$ In the second half of pregnancy, the frequency of GMs gradually decreases, particularly during the last 10 weeks of pregnancy. ${ }^{19}$ In the last trimester of gestation, the range of hand and face movements is the widest. ${ }^{19}$ Fetal neuromuscular development is due to alternate periods of increased and decreased movements, though the exact functional significance of the same is still not understood. ${ }^{20,21}$

The movement in an unstimulated fetus is the result of spontaneous behavior without sensory stimulation and is the best method to assess its CNS capacity, ${ }^{5}$ and can be used as a marker for fetal brain status. ${ }^{22}$ Any fetal brain insult will interfere with endogenous motor activity of the fetus. Genetic factors, external stimuli, pathological conditions, or even environmental changes can affect the fetal human brain up to a degree that may be difficult to assess, especially prenatally. Most of the times, the neurological damage and its effects are difficult to predict. ${ }^{23}$ Establishment of neural connections as a developmental process leads to development of new movement patterns of fetus or transformation of existing patterns. ${ }^{24}$

Integrity of the fetal CNS can be assessed by behavioral states of the fetus, viz., movement of individual organs 

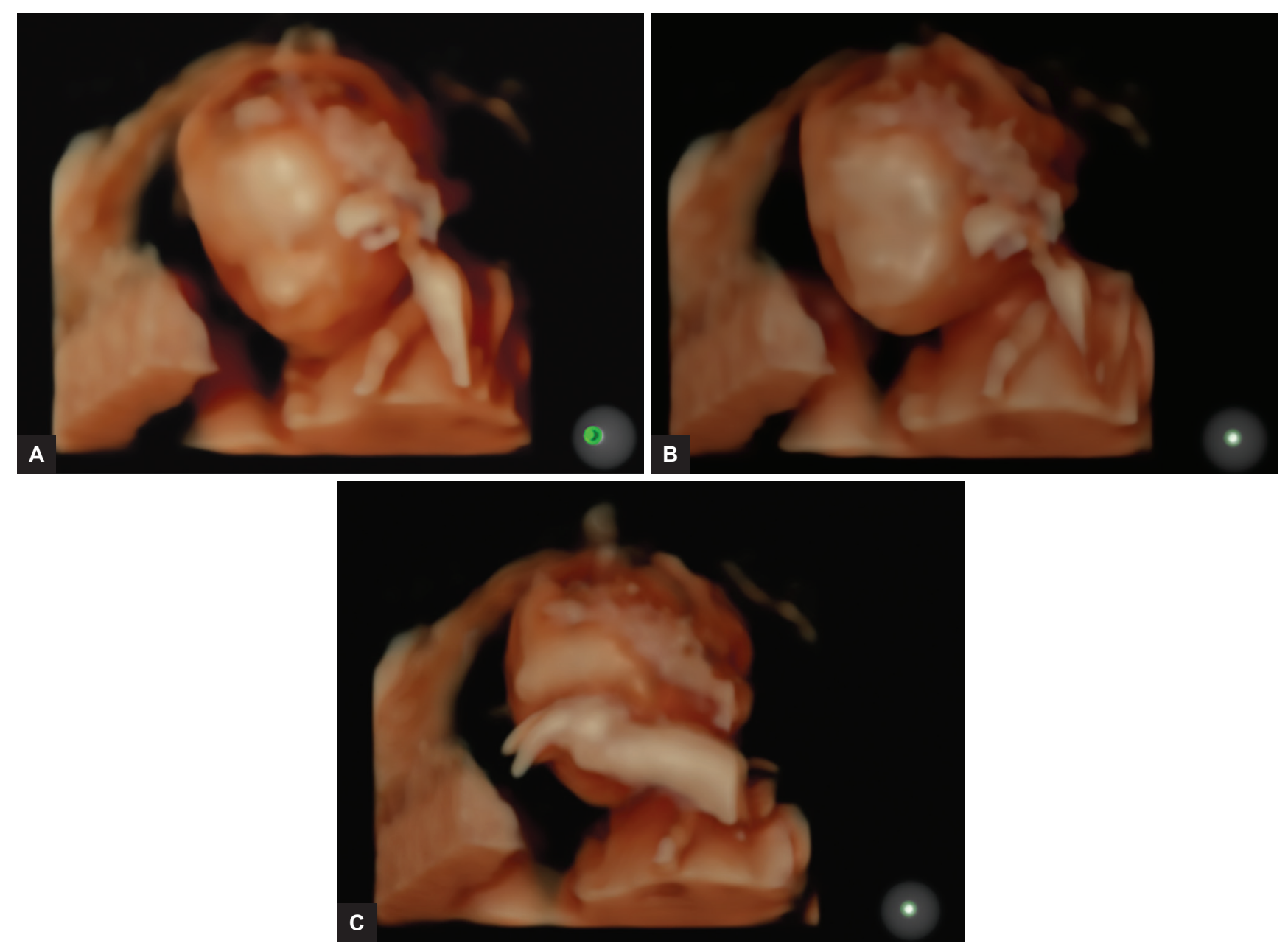

Figs $1 \mathrm{~A}$ to $\mathrm{C}$ : This series of three pictures shows three different positions of hand (A to $C$ ) as three instances of the entire movement of hand to face

like head, trunk, or limbs in an unstimulated but awake fetus and also by qualitative assessment of GMs. ${ }^{25}$ When fetal behavior is studied by 4D US, the altered movement pattern can diagnose abnormal brain development and assist early diagnosis of various abnormalities. ${ }^{26-28}$

The centers in the cerebellum impose controls on the unrestricted movements induced by the lower centers of the brain. ${ }^{19}$ The movements also become more complex as pregnancy advances, which represents the cerebral maturation. Inhibition is a marker of neurological development (especially cortical centers) and most longitudinal studies have also proved that the fetus becomes less active as gestation advances. ${ }^{29}$ Movements observed and analyzed in second and third trimesters are shown in Table 1.

The spinothalamic tract is established at the 20th week and myelinized by 29 weeks of gestation and the thalamocortical connections penetrate the cortical plate at 24 to 26 weeks. ${ }^{16}$ Evoked potentials can be detected from the cortex at the 29th week, indicating that the functional connection between periphery and cortex operates from that time onward. ${ }^{30,31}$ This is because of
Table 1: Types of hand and facial movements in fetus ${ }^{28}$

\begin{tabular}{ll}
\hline Hand and head movements & Facial expression \\
\hline - Head retroflexion & - Isolated eye blinking \\
- Head rotation & - Mouthing \\
- Head anteflexion & - Yawning \\
- Hand to head direction & - Tongue expulsion \\
- Hand to eye & - Grimacing \\
- Hand to mouth & - Swallowing \\
- Hand to face & \\
- Hand to ear & \\
\hline
\end{tabular}

maturation process in the brainstem. ${ }^{32}$ Facial expressions are representation of the maturation of the brain. Expressions like grimacing, tongue expulsion, and eyelid movements (Fig. 2) similar to emotional expressions in adults can be seen by 4 D US. ${ }^{17}$

General movements or gestalt perception ${ }^{33}$ involve the whole body in a variable sequence of arm, leg, neck, and trunk movements. The movements increase and decrease in intensity, but are fluent and elegant, complex, and variable. These are called fetal or preterm from 28 to 36 , and to 38 weeks of postmenstrual age. General movements are considered to be a better predictor of 

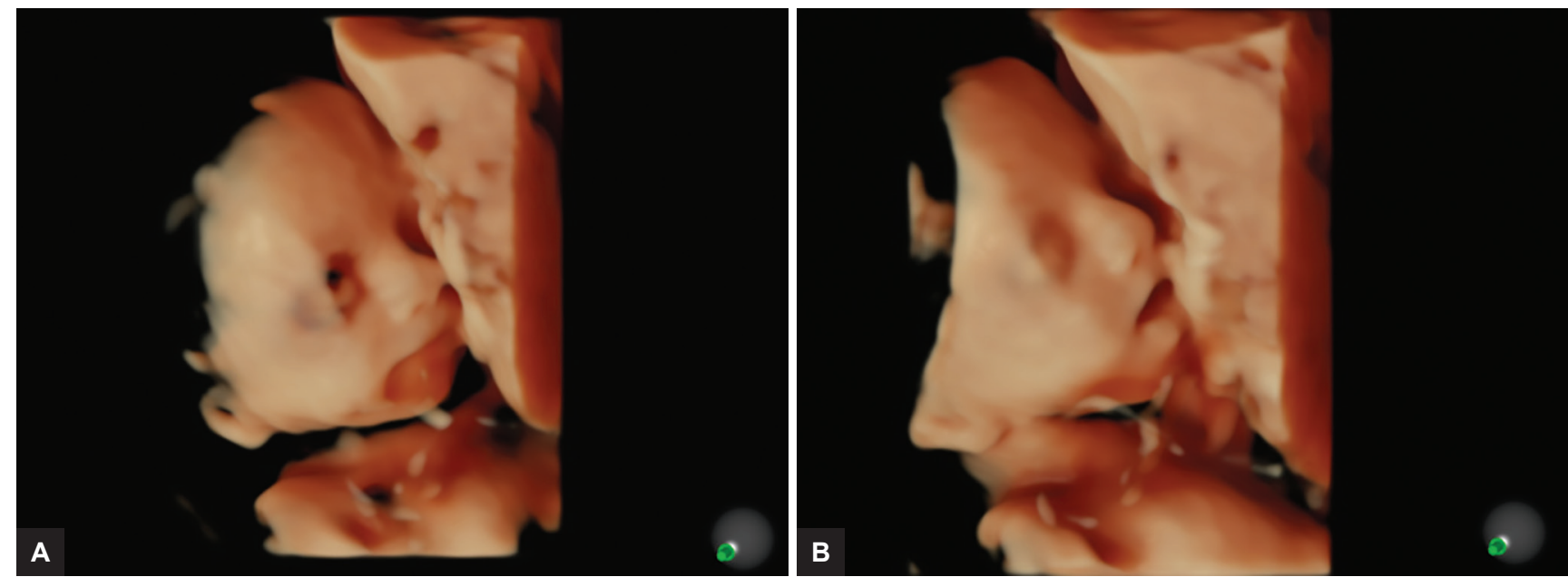

Figs 2A and B: Eyelid and lip movements. (A) The eye is open and mouth closed. (B) Eye is closed and the mouth is open in the same fetus

postnatal neurological disability than clinical neurological examination alone. ${ }^{33}$

Normal GMs are complex but fluent and involve neck, trunk, and limb movements. Moreover, these should also increase and decrease in their intensity. ${ }^{34}$ General movements are complex and fluent and also are not repetitive. ${ }^{35}$ If that is not the case, they are considered abnormal. ${ }^{15,35}$ Slow, monotonous repetitive movements mimicking cramps are abnormal movements. Even when the movements are occurring with generalized simultaneous muscle contractions and relaxations, it is considered abnormal pattern. ${ }^{5,22}$ These also may show variability in strength and the amplitude of movements. ${ }^{22}$ These are often seen in the fetuses of mothers with diabetes mellitus, and also other pregnancies at risk like intrauterine growth retardation (IUGR), pregnancy-induced hypertension, and prematurity. ${ }^{15}$ Both term and preterm newborns, who had cerebral insult of any type during their prenatal period may also show abnormal general movement. ${ }^{11}$ The identification of fetal CNS depression is based on precompetencies (opening of eyes, variety of facial expressions) along with the primary reflexes (rhythmical bursts in the sucking pattern) and quality of GMs. ${ }^{5,36}$

Evaluation of GMs must be done on video recordings, may it be prenatal or postnatal. These must be evaluated with "gestalt perception," which could be described as overall impression of GMs with standardized procedure. It is important to recognize, document, and classify the movement pattern and then their complexity, variability, and fluency. ${ }^{23}$ These can be classified as normal-optimal, normal-suboptimal, mildly abnormal, and definitely abnormal. ${ }^{5,11}$ Quality of neurological movement is more important than the quantity. They can better predict neurodevelopmental outcome than classical neurologic examination alone. ${ }^{37}$

\section{Why do Fetuses of Diabetic Mothers have Higher Risk of Neurological Derangements?}

Gestational diabetes mellitus carries with it multiple risk factors for the developing fetus, and each has independent effects on neurodevelopment that may impact mnemonic behavior. $^{38}$ These risk factors are: (1) Chronic hypoxia, ${ }^{39}$ (2) hyperglycemia/reactive hypoglycemia, and (3) iron deficiency. ${ }^{40}$ Based on the animal models, these factors selectively affect regions of the fetal brain that are involved in explicit memory (e.g., the hippocampus). ${ }^{38,41-43}$

Women with diabetic vascular disease have the highest malformation rates, leading to the belief that vascular disease and hypoxia are teratogenic. ${ }^{43}$

Maternal ketonuria in diabetic mothers is associated with reduced intelligence quotient in their infants, ${ }^{43-45}$ as ketones may interfere with normal development of fetal brain. ${ }^{43}$ Abnormal protein synthesis might also result from a lack of glucogenic amino acids or an overabundance of branched-chain amino acids, as is seen in poorly controlled diabetes. ${ }^{43,46}$

Jovanovic et $\mathrm{al}^{48}$ were able to study the pregnancy in diabetic women before the 10 th week of gestation. Women with uncontrolled diabetes had estradiol, prolactin, and human chorionic gonadotropin levels below the range associated with normal pregnancy. ${ }^{43}$

When these risk factors co-occur, oxygen consumption of the fetus increases and causes fetal hypoxia, ${ }^{38,48}$ which can ultimately result in brain iron deficiency through shifting of available fetal iron away from the brain and into the expanding red cell mass. ${ }^{38,40}$ Prenatal hypoxia and hyperglycemia/reactive hypoglycemia cause poor behavioral and neurologic outcomes presenting as motor and cognitive deficits in humans ${ }^{40}$ and damage to memory areas, such as the cerebral cortex, striatum, and hippocampus in animal models. ${ }^{38,49}$ These factors together lead 
to altered normal maturation of the behavioral states in fetuses with IUGR, maternal diabetes mellitus, or alcohol consumption. ${ }^{50}$

\section{What to Observe for?}

\section{Assessment of Neurological Function}

Even when these movements were documented by $4 \mathrm{D}$ US, it was a very difficult task to classify these movements and based on these to judge the neurological developmental status of fetus. For the first time, a test was structured to assess the fetal CNS integrity and was named as Kurjak's antenatal neurodevelopmental test (KANET). ${ }^{51}$ The KANET is the first test that is based on 4D US, with an original scoring system and has been standardized, so it can be implemented in everyday practice, overcoming the practical difficulties and covering the gaps of methods that were used in the past for the evaluation of fetal behavior. ${ }^{52,53}$ Improvement of 4D ultrasonography technology enabled introduction of KANET, which is a powerful tool in the assessment of fetal behavior and a guide to predict cerebral palsy. ${ }^{54}$ After experimental use for 10 years, a consensus was passed in Bucharest, concluding that KANET test can be used in everyday clinical practice for follow-up of fetuses at neurological risk with strong recommendations for strict and reliable multidisciplinary postnatal follow-up for at least 3 years. It has acceptable sensitivity, specificity, positive, and negative predictive value for neurodevelopmental anomalies. ${ }^{55}$

The test is of more significance than the morphological studies of the brain. Analysis of the fetal behavior compared with morphological studies has concluded that fetal behavioral patterns are direct reflection of developmental and maturational processes of fetal CNS. ${ }^{56}$ The parameters that have been incorporated in the KANET test are isolated head anteflexion, overlapping cranial sutures, head circumference, isolated eye blinking, facial alterations, mouth opening (yawning or mouthing), isolated hand and leg movements and thumb position, and Gestalt perception of GMs. ${ }^{43,57}$

Based on multicentric studies over several years, and on the theory of central pattern generators for GMs, certain fetal movements were chosen as parameters to assess neurological development. ${ }^{57,58}$ It is to be performed between 28 and 38 weeks, when fetus is awake. Fetus is observed for 15 to 20 minutes. If fetus is asleep, the scan is repeated after 30 minutes or after 14 to 16 hours. Each movement depending on its frequency is given a score of 0,1 , and 2 for nine parameters. A score of 0 to 5 is abnormal, a score of 6 to 13 is borderline and a score of more than 14 is normal. ${ }^{59}$ If the test is abnormal or borderline, it is to be repeated every 2 weeks, till delivery (Table 2). ${ }^{58}$

Table 2: Score chart of fetal movements according to KANET ${ }^{62}$

\begin{tabular}{|c|c|c|c|c|}
\hline \multirow[b]{2}{*}{ Sign } & \multicolumn{3}{|c|}{ Score } & \multirow{2}{*}{$\begin{array}{l}\text { Sign } \\
\text { Score }\end{array}$} \\
\hline & 0 & 1 & 2 & \\
\hline Isolated head anteflexion & Abrupt & $\begin{array}{l}\text { Small range ( } 0-3 \text { times of } \\
\text { movements) }\end{array}$ & $\begin{array}{l}\text { Variable in full range, many } \\
\text { alternation ( }>3 \text { times of } \\
\text { movements) }\end{array}$ & \\
\hline
\end{tabular}

Cranial sutures and head Overlapping of cranial circumference sutures

Isolated eye blinking Not present
Normal cranial sutures with measurement of $\mathrm{HC}$ below or above the normal limit (-2 SD) according to GA

Not fluent (1-5 times of blinking)
Fluency ( $>5$ times of blinking)

Normal cranial sutures with normal measurement of $\mathrm{HC}$ according to $\mathrm{GA}$

Facial alteration $\quad$ Not present Not fluent ( $1-5$ times of alteration) Fluency $(>5$ times of alteration)
(grimace or tongue
expulsion)


$($ Cont'd...)

\begin{tabular}{lllll} 
& & & Score & Sign \\
\cline { 2 - 4 } Sign & 0 & 1 & 2 & Score \\
\hline
\end{tabular}

Mouth opening (yawning

or mouthing)

Isolated leg movement Cramped Poor repertoire or small in range ( $0-5$ times of movement)
Variable in full range, many alternation ( $>5$ times of movements)
Isolated hand movement Cramped or abrupt

Hand to face movements
Unilateral or bilateral clenched fist, (neurological thumb)
Poor repertoire or small in range (0-5 times of movement)
Variable in full range, many alternation ( $>5$ times of movements)
Fingers movements
Cramped invariable finger movements
Smooth and complex, variable finger movements

\section{Neurological Function in Fetus of a Diabetic Female}

The results of a study by Edelberg et $\mathrm{al}^{69}$ and Robertson and Dierker ${ }^{21}$ have shown that it is actually the changing maternal blood glucose level that affects the cyclicity and frequency of fetal motor activity, rather than persistently high blood glucose levels. ${ }^{60}$

Visser et $\mathrm{ll}^{61}$ and Schulte et al ${ }^{79}$ studied the neurological development of infants of diabetic mothers (IDMs) and found longer rapid eye movement sleep in newborn IDMs. There is evidence that it is the concurrent maternal blood glucose levels according to which the fetal movements may be affected in diabetic and nondiabetic pregnancies, but different studies have mixed results. Some studies have reported increased and some have shown decreased fetal movement with elevated blood glucose levels. ${ }^{21,62-67}$

Some have reported decreased fetal movement, ${ }^{68-70}$ and others have reported no effects. ${ }^{71-75}$ An increased rate of minor neurological dysfunction was found in a group of 32 children born to mothers with gestational diabetes, including some fine and gross motor deficits, compared with a group of control children. ${ }^{76,77}$
Abnormalities in the fetal motor activity may consist of a delayed first emergence of specific movements, quantitative changes, and an abnormal quality of movements (i.e., changes in execution of movement patterns) and abnormal development of fetal behavioral states. ${ }^{49,55,56}$ Qualitative and quantitative assessment of fetal movements can be used for the recognition of cerebral dysfunctions and probably neuromuscular ailments. Alteration in the normal movement pattern in terms of frequency and strength is seen in IUGR, the pathophysiology of which is fetal hypoxia. In the fetuses of diabetic mothers, fetal hypoxia is the main pathophysiological factor and so similar changes in fetal movements can be observed. A study on diabetesrelated influence on fetal motor activity revealed 1 to 2 weeks delayed appearance of almost all fetal behavioral patterns in the first 12 weeks of pregnancy except the fetal breathing movements. ${ }^{15,49}$

Fetal breathing pattern is considered to be one of the important parameters of fetal wellbeing in late diabetic pregnancies. It is not affected by Braxton-Hicks contractions. This means that the fetal neural control of fetal breathing like movements differ in diabetic pregnancy than in normal. ${ }^{15,78}$ 


\section{Cyclic Motility}

Other aspects of fetal neurobehavioral organization are influenced by the altered metabolic environment. ${ }^{21,69,79-88}$ In spite of good clinical control of diabetes, the infants of these mothers have a risk of compromised neurological developmental outcome. ${ }^{21,89-97}$

Spontaneous fetal movement in the last trimester of human gestation is dominated by irregular oscillations on a scale of minutes [cyclic motility (CM)]. ${ }^{21}$ The movement pattern (increased and decreased movements in cyclicity in normal females) is steady but is altered in mothers with increased blood glucose levels. ${ }^{21}$ Early in the third trimester, changes in the rate of oscillation in fetal CM between the two periods of activity were inversely related to changes in maternal blood glucose levels. ${ }^{21}$ It is seen that relatively short-term fluctuation in maternal glucose metabolism, rather than chronically elevated blood glucose, per se, is the effective perturbation of the intrinsic cyclic patterns in spontaneous fetal motor activity in diabetic pregnancies. The results revealed that fetal CM is more sensitive to fluctuations in maternal blood glucose levels during the early part of the third trimester of gestation than during the middle or end of the third trimester. The results suggest that disruption of the temporal organization of spontaneous fetal motor activity in diabetic pregnancies represents an acute response to fluctuations in the metabolic environment rather than alteration of CM development. ${ }^{98,99}$

But according to other studies, the transient abnormality maternal glucose metabolism may affect fetal CM but does not cause any increased risk of poor general developmental outcome in children of diabetic mothers. ${ }^{21,98}$ The effects are similar in the fetuses of mothers with type I or gestational diabetes, and no difference when fetuses later classified as appropriate for large gestational age were considered separately $(p>0.05){ }^{21,98}$

\section{Effect during Infancy and Childhood}

When gross motor functions were studied in children of diabetic mothers by the Bruininks-Oseretsky test of motor proficiency, it was observed that these children were weak performers compared with the controls. ${ }^{76}$ Maternal diabetes adversely affects some fine neurological functions in children at school age, but not their cognitive scores. ${ }^{76}$ These effects are not correlated with the degree of glycemic control. ${ }^{76}$ Developmental delay, learning difficulties at school, and a high rate of attention deficit hyperactivity disorders are more often seen in the children born after high-risk pregnancies. ${ }^{76,100}$ These children in their early school age have more soft neurological signs (signs of mild, nonspecific brain damage), and lower gross and fine motor achievements than pair-matched control children born to nondiabetic mothers. ${ }^{76,101,102}$ Variability in muscle tone (hypertonicity or hypotonicity) may cause delayed or abnormal motor development (Miyahara M, Department of Kinesiology, UCLA; unpublished observations).

Children born to the mothers having IDM had a risk of shorter gestational age [mean 38 weeks, standard deviation (SD) 2], greater standardized birth weight scores (mean 3,797 gm, SD 947), and lower iron stores (mean ferritin concentration $87 \mu \mathrm{g} / \mathrm{L}, \mathrm{SD} 68$ ) in comparison with the control group. ${ }^{38}$

Children born to the mothers whose diabetes was diagnosed late in pregnancy had lower cognitive scores and verbal performance compared with controls. ${ }^{76,103,104}$

\section{Can KANET predict These Abnormalities?}

Kurjak's antenatal neurodevelopmental test can be useful for early diagnosis of neurological disorders that become manifest in perinatal and postnatal period. ${ }^{45}$ The authors observed that a low KANET score is predictive of both intrauterine and neonatal death. ${ }^{52}$ The study demonstrated the evaluated and accepted KANET to detect and discriminate normal and abnormal fetal behavior in normal and in high-risk pregnancies. ${ }^{105}$ Except for higher incidence in the abnormal group, there was no marked difference in the different motor patterns studied. ${ }^{106,107}$

Analysis of sick preterm infants revealed a "reduction of elegance" and fluency, variability, fluctuation in intensity, and speed instead of change in incidence of distinct motor patterns. ${ }^{30,108-110}$ Abo-Yaqoub et $\mathrm{al}^{110}$ showed in their study that the difference between the two groups were isolated head anteflexion (Fig. 3), isolated eye blinking, facial expressions, mouth movements (Fig. 4), finger movements (Fig. 5), isolated hand movements, hand-to-face movements (Fig. 6), and GMs (Fig. 7). For isolated leg movements (Fig. 8), and cranial sutures, the difference was not significant.

Athanasiadis et $\mathrm{al}^{111}$ applied KANET test to assess and compare fetal behavior and neurodevelopment in 152 pregnant women, classified as low-risk $(n=78)$ and high-risk ( $n=74)$ pregnancies in the second and third trimester. ${ }^{38}$ The neurodevelopmental score was statistically significantly higher in the low-risk group compared with the high-risk group, ${ }^{38}$ though the score was higher in diabetes subgroup compared with the IUGR and the preeclampsia subgroup. ${ }^{111}$

\section{CONCLUSION}

Inadequate glycemic control and vascular pathologies are the chief causes of neurological developmental inadequacies in fetuses of diabetic mothers. These can be assessed and predicted antenatally by KANET test. 

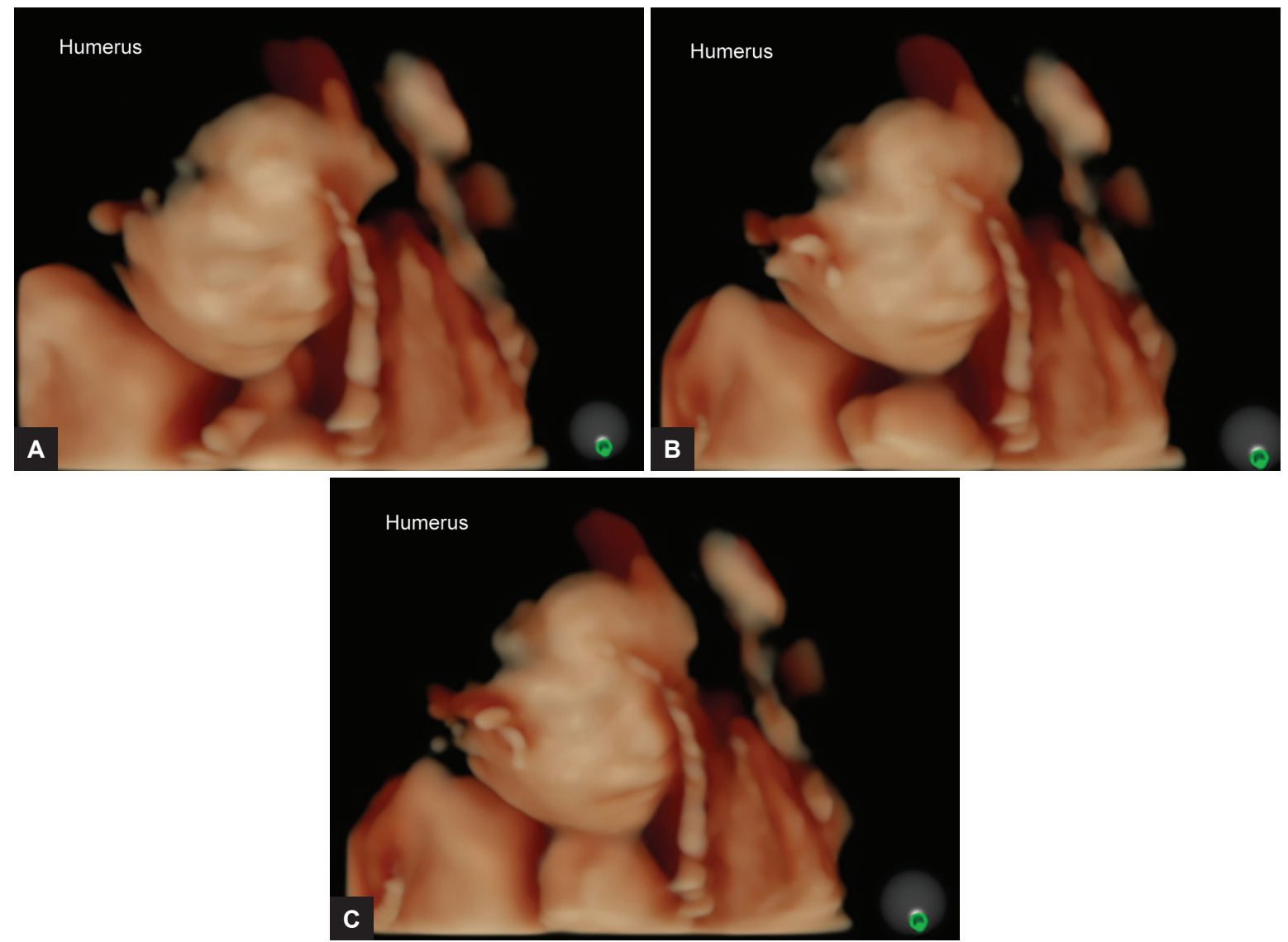

Figs $3 A$ to $C$ : Anteflexion of the head of the fetal head $(A)$, reverted back to the neutral position (B and $C$ ) again shows a slight anteflexion
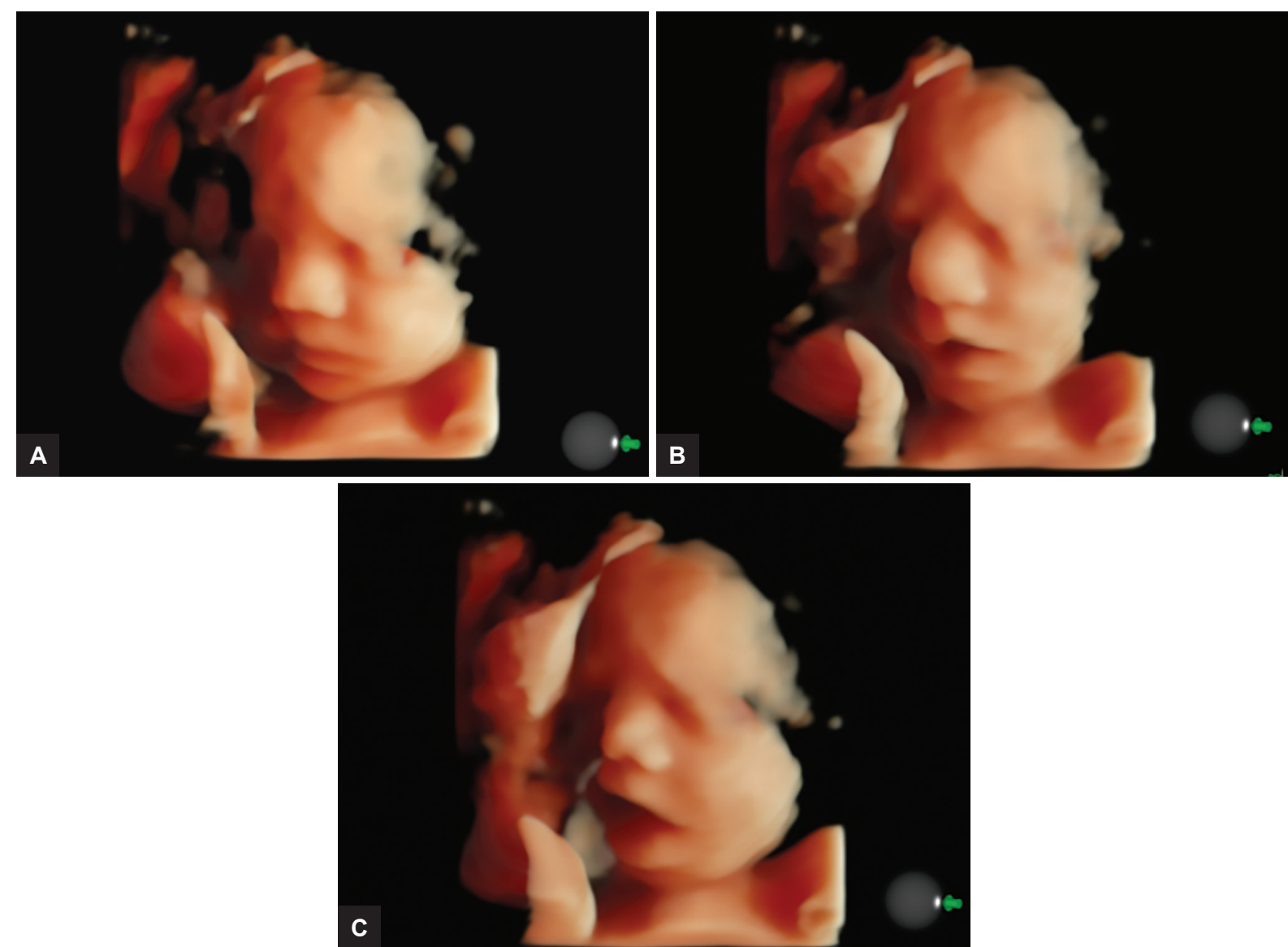

Figs $4 \mathrm{~A}$ to $\mathrm{C}$ : Series of images (A to $\mathrm{C}$ ) show opening of the fetal mouth 


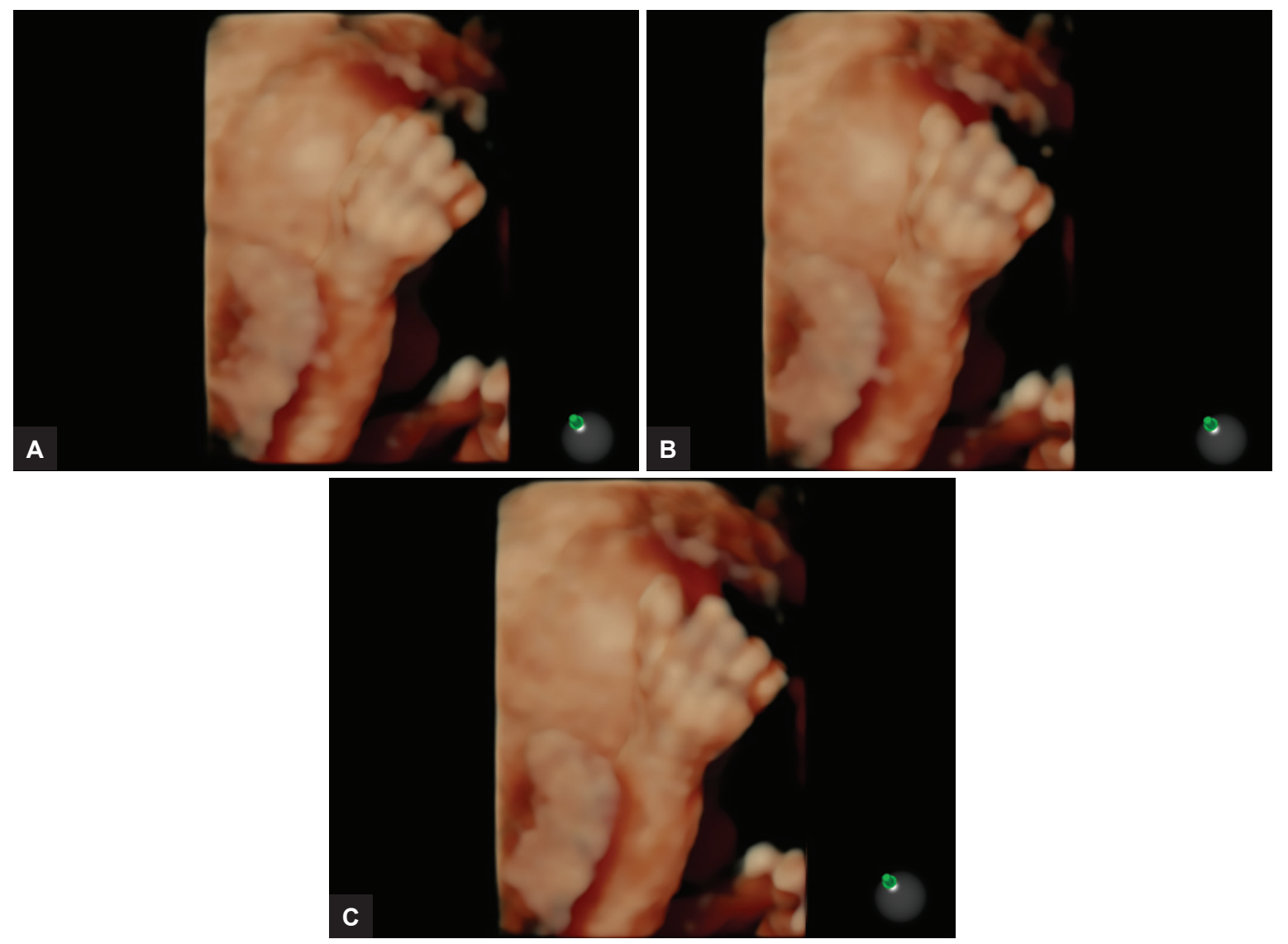

Figs 5A to C: Movement of thumb noted as thumb fixed to fingers and flexed (A), thumb close to fingers but extended $(B)$, and thumb separate from fingers $(C)$
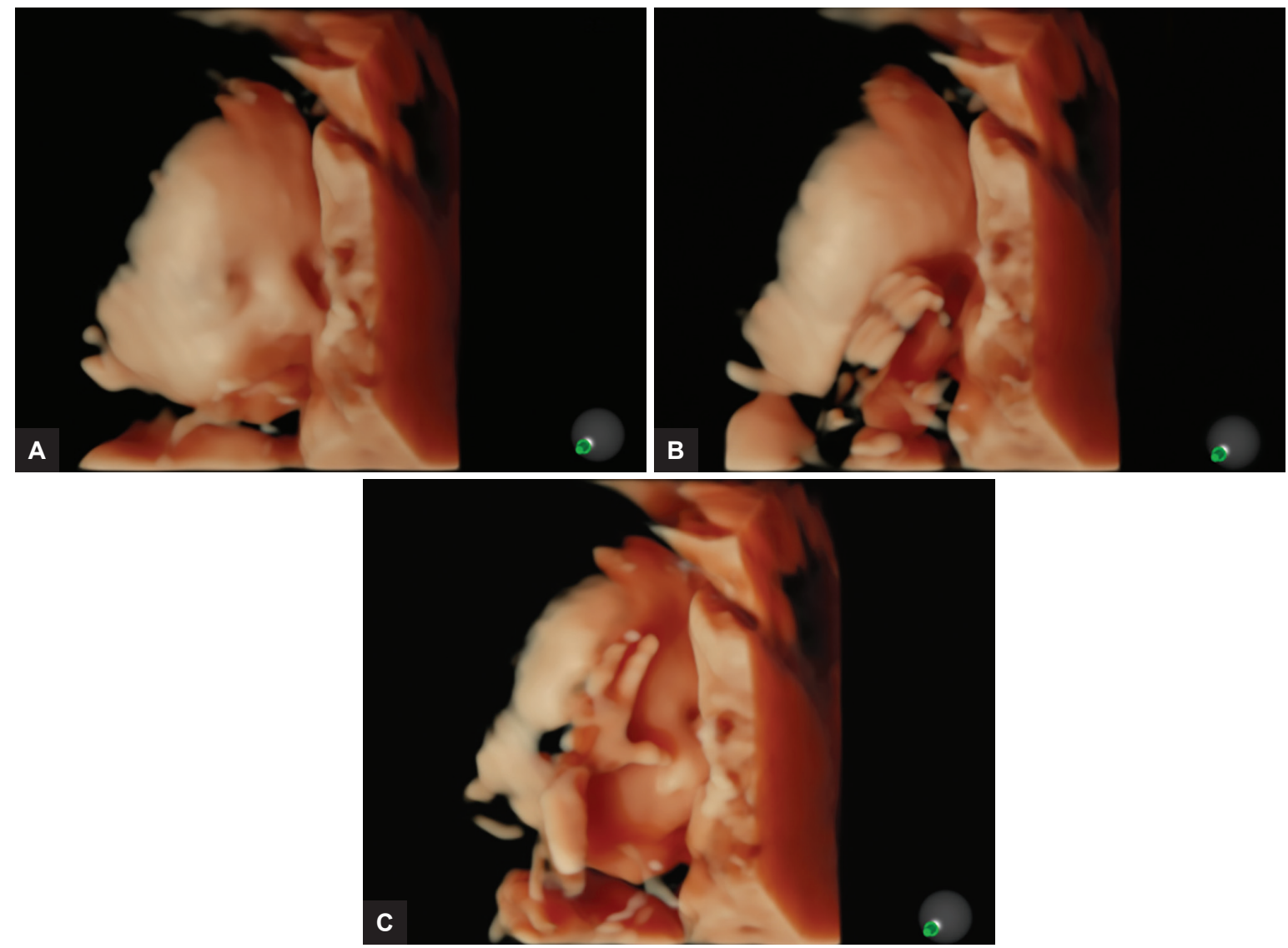

Figs 6A to C: (A) Fetal face with eye open and hand close to the chin. (B) Hand raised to fetal eye and eye is hidden by the hand. $(C)$ Supination of the hand and abduction of thumb and extension of fingers 


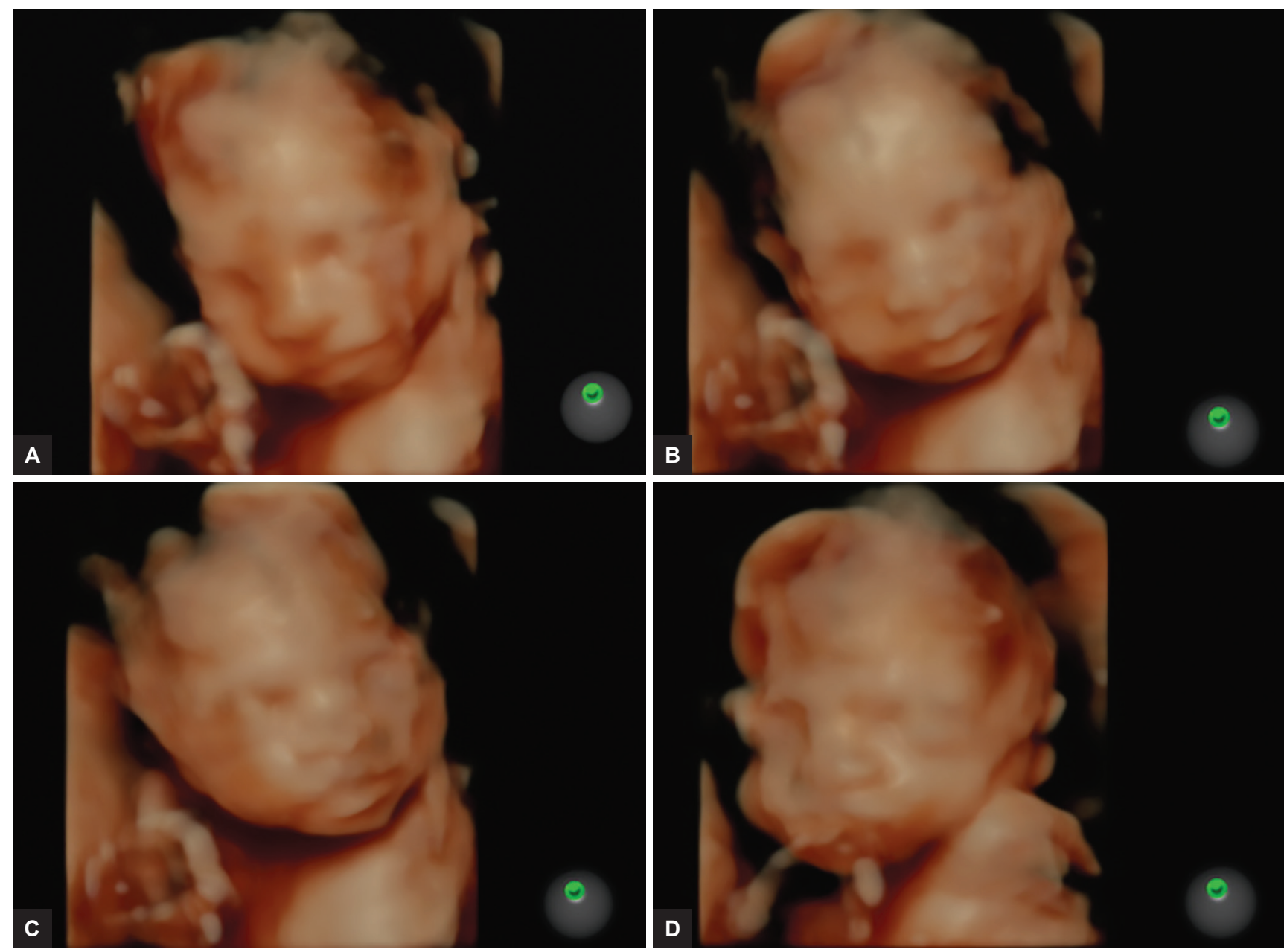

Figs 7A to D: Fetal head rotation and anteflexion movement with movement of the hand (A to D), as a part of general movement

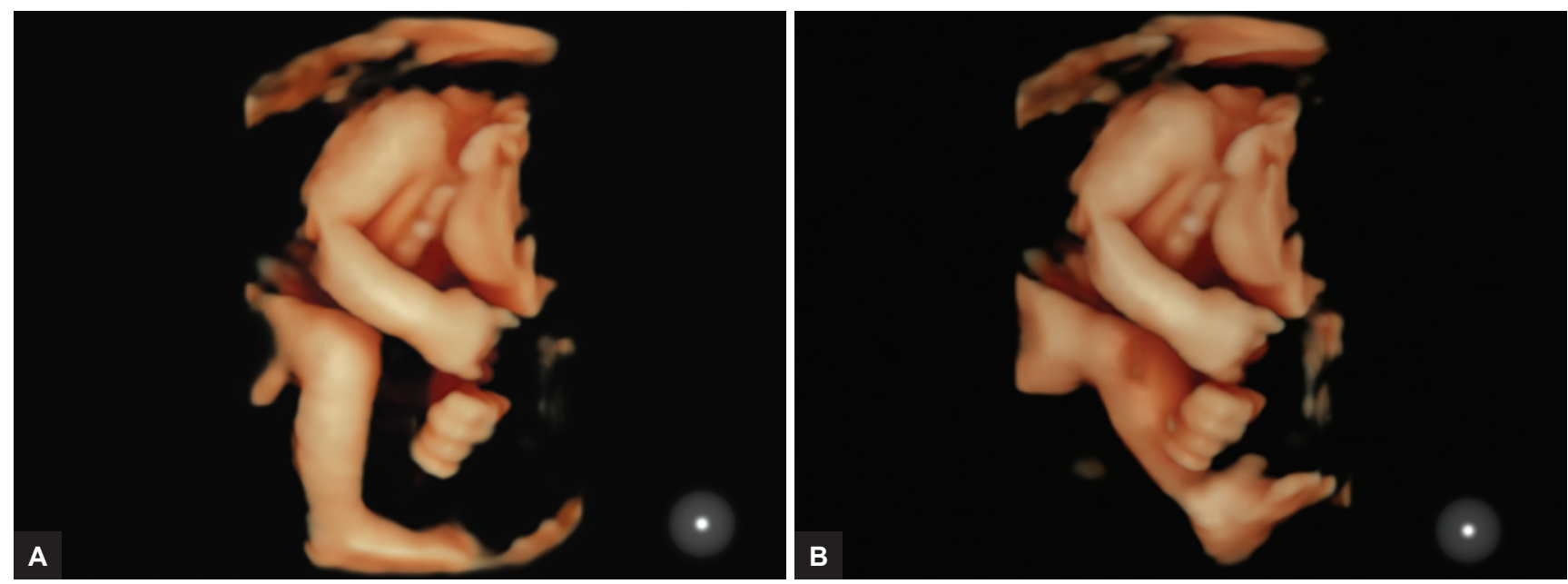

Figs $\mathbf{8 A}$ and $B$ : Partially flexed leg $(A)$ and extension of the same (B)

\section{REFERENCES}

1. Roodenburg PJ, Wladimiroff JW, van Es A, Prechtl HF. Classification and quantitative aspects of fetal movements during the second half of normal pregnancy. Early Hum Dev 1991 Jan-Feb;25(1):19-35.

2. de Vries JI, Fong BF. Normal fetal motility: an overview. Ultrasound Obstet Gynecol 2006 Jun;27(6):701-711.
3. Prechtl HF. Qualitative changes of spontaneous movements in fetus and preterm infant are a marker of neurological dysfunction. Early Hum Dev 1990 Sep;23(3):151-158.

4. DiPietro JA. Neurobehavioral assessment before birth. Ment Retard Dev Disabil Res Rev 2005;11(1):4-13.

5. Kurjak A, Predojevic M, Stanojevic M, Salihagic-Kadic A, Miskovic B, Badreldeen A, Talic A, Zaputovic S, Honemeyer U. 
Intrauterine growth restriction and cerebral palsy. Acta Inform Med 2010 Jun;18(2):64-82.

6. Einspieler C, Prechtl HF, Ferrari F, Cioni G, Bos AF. The qualitative assessment of general movements in preterm, term and young infants-review of the methodology. Early Hum Dev 1997 Nov;50(1):47-60.

7. Moster D, Wilcox AJ, Vollset SE, Markestad T, Lie RT. Cerebral palsy among term and postterm births. JAMA 2010 Sep;304(9):976-982.

8. Yigiter AB, Kavak ZN. Normal standards of fetal behavior assessed by four-dimensional sonography. J Matern Fetal Neonatal Med 2006 Nov;19(11):707-721.

9. Rees S, Harding R. Brain development during fetal life: influences of the intra-uterine environment. Neurosci Lett 2004 May;361(1-3):111-114.

10. Kurjak A, Carrera JM, Stanojevic M, Andonotopo A, Scazzocchio E, Medic M, Salihagic-Kadic A. The role of 4D sonography in the neurological assessment of early human development. Ultrasound Rev Obstet Gynecol 2004;4(3): 148-159.

11. Araki M, Nishitani S, Ushimaru K, Masuzaki H, Oishi K, Shinohara K. Fetal response to induced maternal emotions. J Physiol Sci 2010 May;60(3):213-220.

12. Salihagić-Kadić A, Medić M, Kurjak A, Andonotopo A, Azumendi G, Hafner T, Milenkovic D. Four-dimensional sonography in the assessment of fetal functional neurodevelopment and behavioral patterns. Ultrasound Rev Obstet Gynecol 2005 Jun;5(2):154-168.

13. Andonotopo, W.; Kurjak, A.; Azumendi, G. Ultrasound studies on early pregnancy. In: Carrere JM, Kurjak A, editors. Atlas of clinical application of ultrasound in obstetrics and gynecology. 1st ed. New Delhi: Jaypee Brothers Medical Publishers (P) Ltd; 2006.

14. Kurjak A, Predojevic M, Stanojevic M, Talic A, Honemeyer U, Salihagic-Kadic A. The use of 4D imaging in the behavioral assessment of high risk fetuses. Imaging Med 2011 Oct;3(5): 557-569.

15. Azumendi, G.; Arenas, JB.; Andonotopo, W.; Kurjak, A. Threedimensional sonoembryology. In: Kurjak A, Arenas JB, editors. Donald school textbook of transvaginal sonography. 1st ed. New Delhi: Jaypee Brothers Medical Publishers (P) Ltd; 2006.

16. Kurjak A, Carrera J, Medic M, Azumendi G, Andonotopo W, Stanojevic M. The antenatal development of fetal behavioral patterns assessed by four-dimensional sonography. J Matern Fetal Neonatal Med 2005 Jun;17(6):401-416.

17. Andonotopo W, Medic M, Salihagic-Kadic A, Milenkovic D, Maiz N, Scazzocchio E. The assessment of fetal behavior in early pregnancy: comparison between $2 \mathrm{D}$ and $4 \mathrm{D}$ sonographic scanning. J Perinat Med 2005 Dec;33(5):406-414.

18. de Vries JI, Visser GH, Prechtl HF. The emergence of fetal behavior. I. Qualitative aspects. Early Hum Dev 1982 Dec;7(4): 301-322.

19. D'Elia A, Pighetti M, Moccia G, Santangelo N. Spontaneous motor activity in normal fetuses. Early Hum Dev 2001 Dec;65(2):139-147.

20. Kurjak A, Stanojevic M, Andonotopo W, Salihagic-Kadic A, Carrera JM, Azumendi G. Behavioral pattern continuity from prenatal to postnatal life-a study by four-dimensional (4D) ultrasonography. J Perinat Med 2004 Feb;32(4):346-353.

21. Robertson SS, Dierker LJ. Fetal cyclic motor activity in diabetic pregnancies: sensitivity to maternal blood glucose. Dev Psychobiol 2003 Jan;42(1):9-16.
22. Einspieler, C.; Prechtl, HF.; Bos, A.; Ferrari, F.; Cioni, G. Prechtl's method on the qualitative assessment of general movements in preterm, term and young infants. 1st ed. Cambridge: Mac Keith Press; 2008.

23. Yan F, Dai SY, Akther N, Kuno A, Yanagihara T, Hata T. Fourdimensional sonographic assessment of fetal facial expression early in the third trimester. Int J Gynecol Obstet 2006 Aug;94(2):108-113.

24. Robertson, SS. Mechanism and function of cyclicity in spontaneous movement. In: Smotherman WP, Robinson SR, editors. Behavior of the fetus. Caldwell: Telford Press; 1989. pp. 77-94.

25. Nijhuis, JG. Fetal behavior, developmental and perinatal aspects. Oxford: Oxford University Press; 1992.

26. Kurjak A, Luetic AT. Fetal neurobehavior assessed by threedimensional/four-dimensional sonography. Zdrav Vestn 2010 Nov;79:790-799.

27. Amiel-Tison C, Gosselin J, Kurjak A. Neurosonography in the second half of fetal life: a neonatologist's point of view. J Perinat Med 2006 Feb;34(6):437-446.

28. Kurjak A, Azumendi G, Vecek N, Kupesic S, Solak M, Varga D, Chervenak F. Fetal hand movements and facial expression in normal pregnancy studied by four-dimensional sonography. J Perinat Med 2003 Feb;31(6):496-508.

29. Ten Hof J, Nijhuis IJ, Mulder EJ, Nijhuis JG, Narayan H, Taylor DJ, Westers P, Visser GH. Longitudinal study of fetal body movements: nomograms, intrafetal consistency, and relationship with episodes of heart rate patterns A and B. Pediatr Res 2002 Oct;52(4):568-575.

30. Kurjak A, Andonotopo W, Stanojevic M, Khenyab N, Saleh N, Al-Mansoori Z. Fetal behavioural and structural abnormalities in high risk fetuses assessed by $4 \mathrm{D}$ sonography. Ultrasound Rev Obstet Gynecol. 2005;5(4):259-274.

31. Kostovic I, Rakic P. Development of prestriate visual projections in the monkey and human fetal cerebrum revealed by transient cholinesterase staining. J Neurosci 1984 Jan;4(1):25-42.

32. Joseph R. Fetal brain behavior and cognitive development. Dev Rev 2000 Mar;20(1):81-98.

33. Prechtl HF, Einspieler C. Is neurological assessment of the fetus possible? Eur J Obstet Gynecol Reprod Biol 1997 Dec;75(1):81-84.

34. Hadders-Algra M, Klip-Van den Nieuwendijk A, Martijn A, van Eykern LA. Assessment of general movements: towards a better understanding of a sensitive method to evaluate brain function in young infants. Dev Med Child Neurol 1997 Feb;39(2):88-98.

35. Salihagić-Kadić A, Medić M, Kurjak A. Neurophysiology of fetal behavior. Ultrasound Rev Obstet Gynecol 2004;4(1):2-11.

36. Kurjak A, Carrera JM, Andonotopo W, Salihagic-Kadic A, Medic M, Azumendi G. Behavioral perinatology assessed by four-dimensional sonography. Perinatal Med 2003;42:582-588.

37. Grant-Beuttler M, Glynn LM, Salisbury AL, Davis EP, Holliday C, Sandman CA. Development of fetal movement between 26 and 36-weeks' gestation in response to vibroacoustic stimulation. Front Psychol 2011 Dec;2:350.

38. DeBoer T, Wewerka S, Bauer PJ, Georgieff MK, Nelson CA. Explicit memory performance in infants of diabetic mothers at 1 year of age. Dev Med Child Neurol 2005 Aug;47(8):525-531.

39. Cioni G, Prechtl HF, Ferrari F, Paolicelli PB, Einspieler C, Roversi MF. Which better predicts later outcome in full-term infants: quality of general movements or neurological examination? Early Hum Dev 1997 Nov;50(1):71-85. 
40. Widness JA, Susa JB, Garcia JF, Singer DB, Sehgal P, Oh W, Schwartz R, Schwartz HC. Increased erythropoiesis and elevated erythropoietin in infants born to diabetic mothers and in hyperinsulinemic rhesus fetuses. J Clin Invest 1981 Mar;67(3):637-642.

41. Petry CD, Eaton MA, Wobken JD, Mills MM, Johnson DE, Georgieff MK. Iron deficiency of liver, heart, and brain in newborn infants of diabetic mothers. J Pediatr 1992 Jul;121(1):109-114.

42. Barks JD, Sun R, Malinak C, Silverstein FS. gp120, an HIV-1 protein, increases susceptibility to hypoglycemic and ischemic brain injury in perinatal rats. Exp Neurol 1995 Mar;132(1):123-133.

43. Mills JL. Malformations in infants of diabetic mothers. Birth Defects Res A Clin Mol Teratol 2010 Oct;88(10):769-778.

44. de Deungria M, Rao R, Wobken JD, Luciana M, Nelson CA, Georgieff MK. Perinatal iron deficiency decreases cytochrome c oxidase (CytOx) activity in selected regions of neonatal rat brain. Pediatr Res 2000 Aug;48(2):169-176.

45. Churchill JA, Berendes HW, Nemore J. Neuropsychological deficits in children of diabetic mothers. A report from the Collaborative Study of Cerebral Palsy. Am J Obstet Gynecol 1969 Sep;105(2):257-268.

46. Stehbens JA, Baker GL, Kitchell M. Outcome at ages 1, 3, and 5 years of children born to diabetic women. Am J Obstet Gynecol 1977 Feb;127(4):408-413.

47. Felig P, Marliss E, Ohman JL, Cahill CF Jr. Plasma amino acid levels in diabetic ketoacidosis. Diabetes 1970 Oct;19(10): 727-728.

48. Jovanovic L, Peterson CM, Saxena BB, Dawood MY, Saudek $\mathrm{CD}$. Feasibility of maintaining normal glucose profiles in insulin-dependent pregnant diabetic women. Am J Med 1980 Jan;68(1):105-112.

49. MorokumaS, Fukushima K, Yumoto Y,Uchimura M, Fujiwara A, Matsumoto M, Satoh S, Nakano H. Simplified ultrasound screening for fetal brain function based on behavioral pattern. Early Hum Dev 2007 Mar;83(3):177-181.

50. Horimoto N, Koyanagi T, Maeda H, Satoh S, Takashima T, Minami T, Nakano H. Can brain impairment be detected by in utero behavioral patterns? Arch Dis Child 1993 Jul;69(1 Spec No):3-8.

51. Kurjak A, Andonotopo W, Hafner T, Salihagic Kadic A, Stanojevic M, Azumendi G, Ahmed B, Carrera JM, Troyano JM. Normal standards for fetal neurobehavioral developments: longitudinal quantification by four-dimensional sonography. J Perinat Med 2006 Feb;34(1):56-65.

52. Nijhuis JG, Prechtl HF, Martin CB Jr, Bots RS. Are there behavioral states in the human fetus? Early Hum Dev 1982 Apr;6(2):177-195.

53. Stanojevic M,Antsaklis P,Kadic AS, Predojevic M, VladareanuR, Vladareanu S, Neto RM. Is Kurjak antenatal neurodevelopmental test ready for routine clinical application? Bucharest Consensus Statement. DSJUOG 2015 Jan;9(3):260-265.

54. Rosier-van Dunne FM, van Wezel-Meijler G, Bakker MP, Odendaal HJ, de Vries JI. Fetal general movements and brain sonography in a population at risk for preterm birth. Early Hum Dev 2010 Feb;86(2):107-111.

55. Kurjak A,Stanojevic M, Andonotopo W, Scazzocchio-Duenas E, Azumendi G, Carrera JM. Fetal behavior assessed in all three trimesters of normal pregnancy by four-dimensional ultrasonography. Croat Med J 2005 Oct;46(5):772-780.
56. Stanojevic M, Talic A, Miskovic B, Vasilj O, Shaddad AN, Ahmed B, Kadic AS, Predojevic M, Vladareanu R, Lebit D, Abu-Yaqoub S, et al. An attempt to standardize Kurjak's antenatal neurodevelopmental test: Osaka Consensus Statement. DSJUOG 2011 Oct-Dec;5(4):317-329.

57. Low JA, Galbraith RS, Muir DW, Killen HL, Pater EA, Karchmar EJ. Factors associated with motor and cognitive deficits in children after intrapartum fetal hypoxia. Am J Obstet Gynecol 1984 Mar;148(5):533-539.

58. Kurjak A, Miskovic B, Stanojevic M, Amiel-Tison C, Ahmed B, Azumendi G, Vasilj O, Andonotopo W, Turudic T, SalihagicKadic A. New scoring system for fetal neurobehavior assessed by three- and four-dimensional sonography. J Perinat Med 2008 Feb;36(1):73-81.

59. Nelson C, Silverstein FS. Acute disruption of cytochrome oxidase activity in brain in a perinatal rat stroke model. Pediatr Res 1994 Jul;36(1 Pt 1):12-19.

60. Visser GH, Mulder EJ, Tessa Ververs FF. Fetal behavioral teratology. J Matern Fetal Neonatal Med 2010 Oct;23(Suppl 3):14-16.

61. Visser GH, Bekedam DJ, Mulder EJ, van Ballegooie E. Delayed emergence of fetal behavior in type-1 diabetic women. Early Hum Dev 1985 Nov;12(2):167-172.

62. Aladjem S, Feria A, Rest J, Gull K, O'Connor M. Effect of maternal glucose load on fetal activity. Am J Obstet Gynecol 1979 Jun;134(3):276-280.

63. Eller DP, Stramm SL, Newman RB. The effect of maternal intravenous glucose administration on fetal activity. Am J Obstet Gynecol 1992 Oct;167(4 Pt 1):1071-1074.

64. Gelman SR, Spellacy WN, Wood S, Birk SA, Buhi WC. Fetal movements and ultrasound: effect of maternal intravenous glucose administration. Am J Obstet Gynecol 1980 Jun;137(4):459-461.

65. Goodman JD. The effect of intravenous glucose on human fetal breathing measured by Doppler ultrasound. Br J Obstet Gynecol 1980 Dec;87(12):1080-1083.

66. Miller FC, Skiba H, Klapholz H. The effect of maternal blood sugar levels on fetal activity. Obstet Gynecol 1978 Dec;52(6):662-665.

67. Richardson B, Briggs ML, Toomey C, Burry KJ, O'Grady JP. The effect of maternal glucose administration on the specificity of the nonstress test. Am J Obstet Gynecol 1983 Jan;145(2):141-146.

68. Allen CL, Kisilevsky BS. Fetal behavior in diabetic and nondiabetic pregnant women: an exploratory study. Dev Psychobiol 1999 Jul;35(1):69-80.

69. Edelberg SC, Dierker L, Kalhan S, Rosen MG. Decreased fetal movements with sustained maternal hyperglycemia using the glucose clamp technique. Am J Obstet Gynecol 1987 May;156(5):1101-1105.

70. Holden KP, Jovanovic L, Druzin ML, Peterson CM. Increased fetal activity with low maternal blood glucose levels in pregnancies complicated by diabetes. Am J Perinatol 1984 Jan;1(2):161-164.

71. Bocking AD. Observations of biophysical activities in the normal fetus. Clin Perinatol 1989 Sep;16(3):583-594.

72. Bocking A, Adamson L, Carmichael L, Patrick J, Probert C. Effect of intravenous glucose injection on human maternal and fetal heart rate at term. Am J Obstet Gynecol 1984 Feb;148(4):414-420.

73. Bocking A, Adamson L, Cousin A, Campbell K, Carmichael L, Natale R, Patrick J. Effects of intravenous glucose injections 
on human fetal breathing movements and gross fetal body movements at 38 to 40 weeks' gestational age. Am J Obstet Gynecol 1982 Mar;142(6 Pt 1):606-611.

74. Reece EA, Hagay Z, Roberts AB, DeGennaro N, Homko CJ, Connolly-Diamond M, Sherwin R, Tamborlane WV, Diamond MP. Fetal Doppler and behavioral responses during hypoglycemia induced with the insulin clamp technique in pregnant diabetic women. Am J Obstet Gynecol 1995 Jan;172(1 Pt 1):151-155.

75. Patrick J, Campbell K, Carmichael L, Natale R, Richardson B. Patterns of gross fetal body movements over 24-hour observation intervals during the last 10 weeks of pregnancy. Am J Obstet Gynecol 1982 Feb;142(4):363-371.

76. Ornoy A, Ratzon N, Greenbaum C, Peretz E, Soriano D, Dulitzky M. Neurobehavior of school age children born to diabetic mothers. Arch Dis Child Fetal Neonatal Ed 1998 Sep;79(2):F94-F99.

77. Wolf, A. Developmental evaluation on early school age children born to gestational diabetic mothers. Israel: Hebrew University; 1997.

78. Mulder EJ, Leiblum DM, Visser GH. Fetal breathing movements in late diabetic pregnancy: relationship to fetal heart rate patterns and Braxton Hicks' contractions. Early Hum Dev 1995 Nov;43(3):225-232.

79. Schulte FJ, Michaelis R, Nolte R, Albert G, Parl U, Lasson U. Brain and behavioral maturation in newborn infants of diabetic mothers. I. Nerve conduction and EEG patterns. Neuropadiatrie 1969 Jan-Jul;1(1):24-35.

80. Devoe LD, Youssef AA, Castillo RA, Croom CS. Fetal biophysical activities in third-trimester pregnancies complicated by diabetes mellitus. Am J Obstet Gynecol 1994 Aug;171(2):298-303.

81. Dierker LJ Jr, Pillay S, Sorokin Y, Rosen MG. The change in fetal activity periods in diabetic and nondiabetic pregnancies. Am J Obstet Gynecol 1982 May;143(2):181-185.

82. Doherty NN, Hepper PG. Habituation in fetuses of diabetic mothers. Early Hum Dev 2000 Aug;59(2):85-93.

83. Kainer F, Prechtl HF, Engele H, Einspieler C. Assessment of the quality of general movements in fetuses and infants of women with type-1 diabetes mellitus. Early Hum Dev 1997 Nov;50(1):13-25.

84. Mulder EJ, O'Brien MJ, Lems YL, Visser GH, Prechtl HF. Body and breathing movements in near-term fetuses and newborn infants of type-1 diabetic women. Early Hum Dev 1990 Nov;24(2):131-152.

85. Mulder EJ, Visser GH. Growth and motor development in fetuses of women with type-1 diabetes. I. Early growth patterns. Early Hum Dev 1991 May;25(2):91-106.

86. Mulder EJ, Visser GH. Growth and motor development in fetuses of women with type-1 diabetes. II. Emergence of specific movement patterns. Early Hum Dev 1991 May;25(2):107-115.

87. Mulder EJ, Visser GH. Impact of early growth delay on subsequent fetal growth and functional development: a study on diabetic pregnancy. Early Hum Dev 1992 Dec;31(2):91-95.

88. Mulder EJ, Visser GH, Bekedam DJ, Prechtl HF. Emergence of behavioral states in fetuses of type-1 diabetic women. Early Hum Dev 1987 Jul;15(4):231-251.

89. Mulder EJ, Visser GH, Morssink LP, de Vries JI. Growth and motor development in fetuses of women with type-1 diabetes. III. First trimester quantity of fetal movement patterns. Early Hum Dev 1991 May;25(2):117-133.
90. Aberg A, Westbom L, Kallen B. Congenital malformations among infants whose mothers had gestational diabetes or preexisting diabetes. Early Hum Dev 2001 Mar;61(2):85-95.

91. Deregnier RA, Nelson CA, Thomas KM, Wewerka S, Georgieff MK. Neurophysiologic evaluation of auditory recognition memory in healthy newborn infants and infants of diabetic mothers. J Pediatr 2000 Dec;137(6):777-784.

92. Nelson CA, Wewerka S, Thomas KM, Tribby-Walbridge S, deRegnier R, Georgieff M. Neurocognitive sequelae of infants of diabetic mothers. Behav Neurosci 2000 Oct;114(5):950-956.

93. Reece EA, Homko CJ. Infant of the diabetic mother. Semin Perinatol 1994 Oct;18(5):459-469.

94. Reece EA, Homko CJ. Why do diabetic women deliver malformed infants? Clin Obstet Gynecol 2000 Mar;43(1):32-45.

95. Rizzo T, Metzger BE, Burns WJ, Burns K. Correlations between antepartum maternal metabolism and intelligence of offspring. N Engl J Med 1991 Sep;325(13):911-916.

96. Rizzo TA, Metzger BE, Dooley SL, Cho NH. Early malnutrition and child neurobehavioral development: insights from the study of children of diabetic mothers. Child Dev 1997 Feb;68(1):26-38.

97. Schwartz R, Teramo KA. Effects of diabetic pregnancy on the fetus and newborn. Semin Perinatol 2000 Apr;24(2):120-135.

98. Vaarasmaki MS, Hartikainen A, Anttila M, Pramila S, Koivisto M. Factors predicting peri- and neonatal outcome in diabetic pregnancy. Early Hum Dev 2000 Jul;59(1):61-70.

99. Robertson SS, Dierker LJ. Fetal cyclic motor activity in diabetic pregnancies: sensitivity to maternal blood glucose. Dev Psychobiol 2003 Jan;42(1):9-16.

100. Accardo PJ, Blondis TA, Whitman BY. Disorders of attention and activity level in a referral population. Pediatrics 1990 Mar;85(3 Pt 2):426-431.

101. Ornoy A, Uriel L, Tennenbaum A. Inattention, hyperactivity and speech delay at 2-4 years of age as a predictor for ADDADHD syndrome. Isr J Psychiatry Relat Sci 1993;30(3):155-163.

102. Smyth TR. Impaired motor skill (clumsiness) in otherwise normal children: a review. Child Care Health Dev 1992 Sep-Oct;18(5):283-300.

103. Petersen MB, Pedersen SA, Greisen G, Pedersen JF, MølstedPedersen L. Early growth delay in diabetic pregnancy: relation to psychomotor development at age 4. Br Med J (Clin Res Ed) 1988 Feb;296(6622):598-600.

104. Sells CJ, Robinson NM, Brown Z, Knopp RH. Long-term developmental follow-up of infants of diabetic mothers. J Pediatr 1994 Jul;125(1):S9-S17.

105. Vladareanu R, Lebit D, Constantinescu S. Ultrasound assessment of fetal neurobehaviour in high risk pregnancies. DSJUOG 2012 Apr-Jun;6(2):132-147.

106. Talic A, Kurjak A, Ahmed B, Stanojevic M, Predojevic M, Kadic AS, Di Renzo GC. The potential of 4D sonography in the assessment of fetal behavior in high-risk pregnancies. J Matern Fetal Neonatal Med 2011 Jul;24(7):948-954.

107. Bekedam DJ, Visser GH, de Vries JJ, Prechtl HF. Motor behaviour in the growth retarded fetus. Early Hum Dev 1985 Nov;12(2):155-165.

108. Cioni G, Prechtl HF. Preterm and early postterm motor behaviour in low-risk premature infants. Early Hum Dev 1990 Sep;23(3):159-191.

109. Seme-Ciglenecki P. Predictive value of assessment of general movements for neurological development of highrisk preterm infants: comparative study. Croat Med J 2003 Dec;44(6):721-727. 
110. Abo-Yaqoub S, Kurjak A, Mohammed AB, Shadad A, Abdel-Maaboud M. The role of 4-D ultrasonography in prenatal assessment of fetal neurobehaviour and prediction of neurological outcome. J Matern Fetal Neonatal Med 2012 Mar;25(3):231-236.
111. Athanasiadis AP, Mikos T, Tambakoudis GP, Theodoridis TD, Papastergiou M, Assimakopoulos E, Tarlatzis BC. Neurodevelopmental fetal assessment using KANET scoring system in low and high-risk pregnancies. J Matern Fetal Neonatal Med 2013 Mar;26(4):363-368. 